\title{
Communicating Queerness in the Communications Classroom
}

\section{DAWN JOHNSTON}

Dawn Johnston (debjohns@ucalgary.ca) is a doctoral candidate in the Faculty of Communication and Culture at the University of Calgary. Her research explores queer urban space, public spectacle, and uses of various media by queer activists. This essay, first presented at the 2000 CLGSA conference in Edmonton, is an experiential reflection on first-time teaching of queer theory in undergraduate Communications Studies courses.

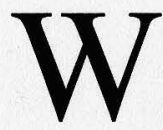

hen I was in the third year of my undergraduate English degree at Memorial University in Newfoundland in 1995 ,

I gave a class presentation on homoeroticism in the poetry of Alfred, Lord Tennyson. It was the only time that queerness was discussed in any of my English courses. While completing course work for my Master's degree at the University of Calgary in 1998, I presented a paper on queer theory in my communications theory class. It was lumped into the week called "feminist theories," and I was told by the professor that I would have to find some background articles for the class to read in advance, because the theory textbook did not cover it, and he "didn't have any literature on this topic in his files." When I started preparing course outlines for the undergraduate classes I was to teach at the University of Calgary in September, 1999 , I was advised by a colleague that if I was planning to discuss "gay and lesbian issues," I had better add to the outline a warning about "sexually explicit material" in the course that might offend some students. And when, on the first day of classes, I discussed the semester's reading list with my fourth year cultural studies students, the words "queer theory" generated a response that consisted of an equal mix of uncomfortable giggles and blank stares.

I was genuinely surprised (more so than offended) by the

torquere: Journal of the Canadian Lesbian and Gay Studies Association / Revue de la Société canadienne des études lesbiennes et gaies

Vol. 3 (2001) @ CLGSA / SCELG 
responses I received from my professors, my colleagues, and my students when I introduced queer theory - or even my own queerness - into the classroom. My experience as an out lesbian in academia has been nothing but positive - I guess I expected that the level of tolerance and acceptance that my personal life had received would be reflected, at least to some degree, in the response to my academic interest in queerness. If I was not shocking people at the faculty Christmas party, I certainly did not expect to be shocking them in the classroom. But as a student, I felt distinctly isolated in my pursuit of queering communications theory. And as an instructor, my determination to queer the curriculum and the class space has been met with mixed responses. A great deal has been written on why queering the classroom is a useful - even necessary - activity (see Britzman; Bryson/de Castell; Ellsworth; Khayatt; Sedgwick). This paper is about what happened to me when I tried it.

Queer theory's place within communications studies is clear to me. As a field of study, communications is certainly interdisciplinary. It brings together scholars and professionals from a variety of areas media studies, journalism, public relations, and cultural studies, to name a few. But at the simplest level, communications is about the making of meaning. It looks at the way that individuals construct identity, their experiences of self and other, their interactions with their environments and communities. And it is within that core of communications studies that queer theory has a place. Representation and performance are central issues in many contemporary communications theories. Race, class, gender, and more recently, sexual orientation, have been identified as important elements in the marking of 'self' and the construction of 'other' in studies that examine the marginalization of individuals and groups on the basis of such markers. The reason for this is clear: like race, class, and gender, sexual orientation can be understood as a product - and producer of community, identity, and power. Sexual orientation is a powerful site within contemporary popular culture. In turn, the discourses of queer theory make important contributions to the communications discipline as a whole.

And it is not as though no communications theory looks at issues of sexuality or challenges normativity. Some excellent work has been done in the area of queer theory within communications and cultural studies. Queerness on television and in film, queer 
performance and spectacle, queer political activism, and queer urban space have all been tackled deftly and thoughtfully by a variety of communications theorists. So why is it still a shock to so many students - and even to many other professors - when queer theory appears on a syllabus for an undergraduate communications course? Why are so few introductory communications texts even mentioning the ' $q$ ' word, let alone devoting a piece of a chapter to it? Why are so many people questioning whether or not queerness belongs in the classroom?

One answer is obvious. Like sexuality itself, studies of sexuality are contentious and political. Furthermore, like its postmodern roots, queer theory is slippery. Along with bringing the personal into the realm of the political (as though the two were ever mutually exclusive), it insists on breaking down the popular assumptions of individual identity and interpersonal relationships that have been solidified by centuries of heteropatriarchal presumptions. As Donna Haraway says, "social reality is lived social relations" (150). So when I want to start talking about queer theory with my students, I find myself starting at a level far below - or at least far away from the level at which I want them to be thinking about sexuality, power, and identity. In other words, before I can get them to problematize sexual binaries, deconstruct identities, or challenge normativity in any fashion, I first have to get them to say the words, read the articles, and begin the process of questioning the roots of their own assumptions.

In my Communications 201 class - which is the introductory communication theory course usually populated by first year students -feminist theories, standpoint theories, and critical theories in general are 'handled' in just one chapter in the textbook (see Figure 1). The bulk of the course focuses on theoretical traditions in the communications discipline, along with more practical attention to communications careers and interpersonal and group dynamics. So my attempts to queer perspectives or introduce notions that might challenge the heteronormative environment must be made in, for lack of a better term, baby steps.

One activity that $I$ have found to be quite effective early in the term is Julia Wood's "Uncertain Dialogue" (see Figure 2 for full activity description). I provide role-play dialogues between fictional couples and have them acted out both by student pairs of the opposite 
sex and by student pairs of the same sex - an activity that inevitably causes a few volunteers to blush, but has never been received with overt hostility. Not surprisingly, students often incorporate physical stereotypes of gays and lesbians in an effort to break any tension with humor. It is interesting to watch how those physical 'identifiers' are acted out and received by students, and I make a point of investigating those stereotypes in our postactivity discussion.

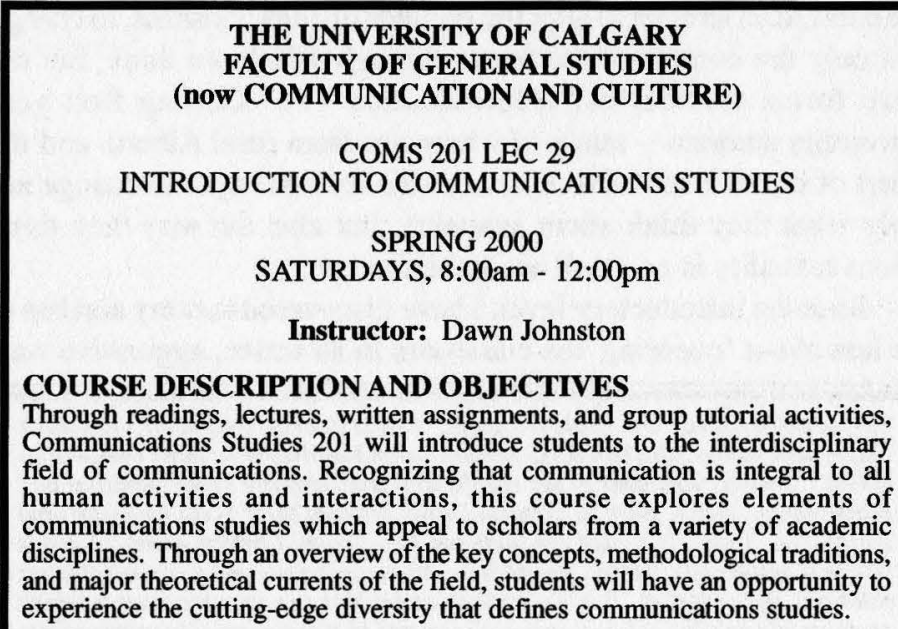

Instructor: Dawn Johnston

\section{COURSE DESCRIPTION AND OBJECTIVES}

Through readings, lectures, written assignments, and group tutorial activities, Communications Studies 201 will introduce students to the interdisciplinary field of communications. Recognizing that communication is integral to all human activities and interactions, this course explores elements of communications studies which appeal to scholars from a variety of academic disciplines. Through an overview of the key concepts, methodological traditions, and major theoretical currents of the field, students will have an opportunity to experience the cutting-edge diversity that defines communications studies.

\section{TEXTBOOKS/READINGS}

Wood, J. (2000). Communication Theories in Action. Toronto: Wadsworth.

Reserve readings as assigned by instructor.

Figure 1

Further along in the semester, I have students get into groups and discuss a series of statements to determine whether the language used is sexist or homophobic (list of statements in Figure 3). Most of the students have no trouble identifying the homophobia in the statement "It's fine for gays to get married but I don't think they should be able to adopt," but fewer immediately identify the heterocentricism in the statement "Bob is a great friend of mine - he's gay, but acts just like a normal guy." One student's response to that comment was "But if he's my friend, and I really like and respect him, how can that be considered homophobic?" Inevitably, several students agree when a 
comment like this is raised. But so far, I have been pleasantly surprised to discover that one of the other students in the class usually jumps in to offer an explanation of why positioning straight as normal positions gay as abnormal - no matter how much liking or respecting might be going on! That recognition of heteronormativity by my students demonstrates a notable shift in thinking for many of them. As Janice Ristock and Catherine Taylor suggest, "convictions about sexuality seem so deeply embraced that setting out to change people's minds amounts to an attempt to alter the grounds of consciousness, to change not only the content of the forms through which we think, but the very forms themselves" ("Introduction" 7). Getting first year university students - many of whom are from rural Alberta and the heart of ultraconservative Reform/Alliance country - to change not only what they think about sexuality, but also the way they think about sexuality is no small accomplishment.

So at the introductory level, I have discovered that my aim has to be less about 'queering' the classroom in an active, aggressive way,

This activity, called "Uncertain Dialogue, ".comes from the Instructor's Resource Guide attached to Julia Wood's Communication Theories in Action (Wadsworth, 2000). Students volunteer to act out the dialogue, and are given identities and relationships which must be communicated through their body language and intonation. I usually assign the dialogue to a fictional heterosexual couple, a fictional gay couple, friends, co-workers, co-conspirators and a variety of other relations and activities. It is particularly interesting to notice the ways in which students rely on physical stereotypes of gays and lesbians in order to communicate their relationship to each other with maximum humour and minimum discomfort. Our discussion at the end of the activity reveals many assumptions and stereotypes that feed great class discussion.

$\begin{array}{ll}\text { 1: } & \text { Hello. } \\ 2: & \text { Hi. } \\ 1: & \text { So, uh, how are you? } \\ 2: & \text { About the same. And you? } \\ \text { 1: } & \text { Nothing new to report. } \\ 2: & \text { I thought maybe you might have something to tell me. } \\ 1: & \text { Why, has anything changed? } \\ 2: & \text { Not that I know of. Do you know of a change? } \\ 1: & \text { No. } \\ 2: & \text { So what do you think we should do now? } \\ 1: & \text { I suppose we could go ahead and... you know... } \\ 2: & \text { Yeah, seems like it's a good idea. } \\ 1: & \text { Are you sure? } \\ 2: & \text { As sure as we ever can be in a situation like this. } \\ 1: & \text { Do you want to reconsider: A lot is at stake here. } \\ 2: & \text { No, I'm ready. Let's do it. }\end{array}$


and more about introducing sexuality as a valid site of inquiry in communications studies. The fourth year cultural studies class that I teach offers much more of a chance to play with queerness. It is at that level that I encourage people to haul out their ideas about 'gay' and 'straight' and 'bent' and 'normal' and all those other loaded words and lay them on the table. Once they are out there, we start messing them around.

The cultural studies course is divided into sections based on major theories of popular culture. We begin the course by looking at mass culture theory, work our way through semiology, structuralism, Marxism, feminism, and postmodernism, and then finish up the course with queer theory (see Figures 4 and 5 for course outline and schedule of readings). The placement of the queer theory segment at the end

I give this list of statements (some of which come from Julia Wood's text) to students in groups of 3-4 people, and have them discuss whether they consider the statements to be in any way racist, sexist or homophobic.

\section{IS OUR LANGUAGE SEXIST, RACIST, AND HOMOPHOBIC?}

Read each of the following ten statements and discuss within your group whether they are sexist, racist, homophobic, or none of the above. You may not be able to reach consensus on the issue, but be prepared to explain your group's discussion.

1. I now pronounce you man and wife.

2. The news program features 'man in the street' interviews.

3. Let's see if we can't make something good happen here by using a little white magic.

4. I was surprised that Anne kept her last name when she got married.

5. John stayed home to babysit his son while his wife went back to the office to finish up some work.

6. I met a female lawyer and a male nurse at the party last night.

7. Blacks are really confrontational.

8. I think that the only way two people can really show their commitment to one another is to get married.

9. My hairdresser, Bob, is gay, but he acts like a regular guy around his clients.

10. I think its fine for gay couples to marry, but I don't think they should be able to adopt.

Figure 3 


\section{4 / Johnston}

of the course is not arbitrary. It is quite by design. The class is small - capped at 25 students - and usually becomes more interactive, open, and comfortable by the final few weeks of the course. As well, I find postmodernism makes for excellent preparation for queer theory. After the class has spent a couple of weeks trying to digest works by Frederic Jameson, Jean Baudrillard, and Michel Foucault, and getting their heads around notions of fluidity, multiplicity, discontinuity, leakiness, marginality, and fragmentation, for example, transferring some of those theoretical building blocks into a discussion about sexual identities seems easy! When we discuss postmodernism, we look at the way in which the abstract is privileged over the linear, and at how traditional valuations of single/unified/one as strong, and multiple/uncertain/fluctuating as weak are broken down (see Hammer 74). So when such postmodern notions are applied to construction and representation of self and identity, the place of queer theory in the class is illuminated. Both theories are full of questions and contradictions, and often focus their energies on complicating and challenging societal traditions and norms. But at the beginning of the term, no one was surprised to hear that we would study postmodern theories. The place of queer theories seemed a little less obvious.

When introducing the segment on queer theory, I made as many connections as possible to other theories that we had covered in the course. Since postmodernism was the freshest in their minds, the connections to it were also the clearest. Queer theory embraces postmodern methods of looking at the world on philosophical, historical, structural, and aesthetic levels by refusing totalizing or essentializing notions of self and other, by acknowledging the fragmentation and discontinuity of identity, and by creating a space in which sexual selves are recognizable as multiple, varied, and responsive to context. As queer theorist James Darsey points out, "the gay liberation movement has a strong claim to being the most thoroughly postmodern, not just in its chronological placement, but in its sanguine acknowledgment of the partiality of the world and the decay of natural law" (47). Like the movement itself, queer theory has a strong claim to postmodernism as the driving force behind the discourse that surrounds both sexual minorities and the scholarly analysis of them. Multiple and contradictory meanings are inherent in rhetorical analysis of sexual orientation.

Thus the connections between queer theory and postmodernism 


THE UNIVERSITY OF CALGARY
FACULTY OF COMMUNICATION AND CULTURE
COMS 441 LEC 60
CULTURAL STUDIES IN COMMUNICATIONS
SUMMER 2000
TUESDAYS AND THURSDAYS, 2:00pm - 4:45pm
Instructor:Dawn Johnston
COURSE DESCRIPTION
This course focuses on the major cultural and critical approaches to studying
and understanding communication. Throughout the course, we will explore the
diverse cultural, historical, and intellectual contexts from which various
theoretical currents have emerged, as well as their roles and applications in
particular cultural texts, practices, and environments. Through a survey of key
concepts and research methods in cultural studies, this course will help students
to question, problematize, and better understand the making of meaning in
mainstream and marginalized communities in our society.
TEXTBOOKS/READINGS
Strinati, D. (1995). An Introduction to Theories of Popular Culture. New
York: Routledge.
Van Luven, Lynne and Priscilla Walton. (1999). Pop Can. Ontario: Prentice
Hall.
Reserve readings as assigned by instructor.

Figure 4

soon become clear to most students. The next obvious link is between queer theory and feminist theories. As Elizabeth Weed says, "when feminism meets queer theory, no introductions seem necessary. Both academic feminism and queer theory are connected, however directly or indirectly, to political movements outside the academy, in some cases to overlapping movements. Both are interdisciplinary modes of inquiry; both constitute themselves in critical relation to a set of hegemonic social and cultural formations" (vii). As Weed points out, feminism and queer theory are inevitably linked by virtue of their commitment to studying marginalities and problematizing stereotypes. Feminism and queer theory are also often linked in their tendency toward academic activism - bringing the personal into the realm of the political, and demanding changes in societal treatment of groups who face systematic discrimination on all levels. Both are 


\section{$106 /$ Johnston}

interdisciplinary, finding their roots as well as their contemporary academic significance in a variety of fields. And both feminism and queer theory are plagued with a constant need - from within and without - to clarify, justify, and redefine the terms that constitute their academic and political language. The word 'feminism' has been and is as widely debated a term as 'queer' will ever be. Also, semantics aside, most queer theorists of today are quick to acknowledge the roads that were paved by yesterday's lesbian feminists - particularly within the second-wave feminist movement - and by the academic recognition of women's studies. All of these points of intersection between feminism and queer theory help students to understand why queer theory belongs in communications and cultural studies.

But in addition to showing students that queer theory is intricately connected to other theories of popular culture, I also take great pains to show them that it is both inadequate and inappropriate to lump queer theory together with those other theories, with the expectation that 'the material will get covered somewhere else.' Because more often than not, the material does not get covered somewhere else. To expect feminist theory, for example, to devote sufficient attention to issues of queerness is unreasonable. While their large-scale goals are comparable, even complementary, the differences, points of disagreement, and perceived responsibilities of feminist and queer theories are both significant and contentious. Surface logic would suggest that since the struggles of women are often similar to the struggles of gays, lesbians, bisexuals, and transgendered people, the communities should band together and create alliances to overcome common obstacles - politically, socially, and academically. But looking deeper into the particular oppressions and experiences of each community indicates that such a suggestion is not just narrowminded - it is inadequate. As Adrienne Rich suggests, we cannot fully comprehend the complexities of homosexuality - as she describes it, the "particular oppressions, meanings, and potentialities" - as long as it is simply bracketed with other marginalized and stigmatized existences (218). She insists that like racism, sexism, and classism, heterosexism is an institution, and that such an oppressive social construct cannot be challenged or deconstructed without specific, focused attention. In this vein, I have my students look through a variety of gay and lesbian magazines and compare their layout, content, and advertising to mainstream heterosexually- 
The following is a list of readings that lead up to and shape my Cultural Studies (COMS 441) class' discussion of queer theory. This list has shifted from semester to semester as I find new readings that stimulate discussion.

Foucault, Michel. The History of Sexuality (Volume One, Chapter One). New York: Random House, 1978.

Gilbert, Sky. "Everybody in Leather." THIS January - February 2000: 12-14. Queen, Carol and Laurence Schimel. Pomosexuals: Challenging Assumptions about Gender and Sexuality. San Francisco: Cleis Press, 1997.

Rich, Adrienne. "Compulsory Heterosexuality and Lesbian Existence." Adrienne Rich's Prose and Poetry. New York: W.W. Norton and Company, 1993.

We also spend class time in small groups looking at a variety of popular gay/ lesbian/bisexual magazines, such as:

$\begin{array}{ll}\text { Curve } & \text { Out } \\ \text { Girlfriends } & \text { Hero } \\ \text { Diva } & \text { Genre }\end{array}$

Figure 5

oriented publications (see Figure 5). I have them discuss representations of various sexual minorities in the news. They watch a series of television shows and films that feature gay and lesbian characters, in search of heterosexual bias and reliance upon stereotypes. Most importantly, perhaps, I encourage them to read and interpret their own identities, sexualities, and communities with a more critical eye.

Getting students to talk about sex is easy. Getting them to let go of - or at least challenge - some deeply held convictions about sexuality and its place in the classroom is a little bit more difficult. To go back to the words of Ristock and Taylor, ideas and value judgments about sexuality are so firmly planted in most of our minds that rethinking them requires us to question not only our ideas, but even the roots and "forms" of our ideas. Such a shift in thinking, or pursuit to "alter the grounds of consciousness" and queer the classroom requires both commitment and sensitivity on the part of the instructor - commitment to encouraging students to unhook binaries and challenge traditional notions of self and identity and sensitivity to the students who are very reluctant to do so. On one of the final exams for this course (see Figure 6 for sample final exam question), I still had one student who chose to define "queer" as 
abnormal like "a lesion, or spiritual ailment." But I also received exam responses like the one that is quoted in part below:

At the beginning of this course, I did not think that sexuality was as valid an area of study in popular culture as race, class, or gender. Having completed the course, now, however, I see it as very valid. Sexuality is as much a part of our identities and our everyday lives as race, class and gender are. Our sexuality is a source for discrimination, and so, much like feminism looks at discrimination against women, queer theory helps us look at discrimination against people of different sexualities. I know that I said [before] that there's something about heterosexuality that just makes sense. But now I also feel it is important to gain an understanding of other different sexualities, and to see how they've been not only misrepresented by the media, but much more often excluded from the mass media. I also feel that there is a need to critically think about ourselves and our sexuality. It is something we don't question enough. I think that it's important to see ourselves as sexually complex, and studying queer theory as an area of popular culture makes that kind of thought process possible. And that, too, is something that just makes sense.

Such a response was incredibly affirming. But, of course, it was the

The following is an essay question option which has appeared on the final exam. It challenges students to both draw on the concepts and theoretical frameworks that we've discussed in class, and develop their own argument about the place of queer theory in communication and cultural studies.

1. In her book entitled Pomosexuals: Challenging Assumptions about Gender and Sexuality, Carol Queen says of queerness that it "lives in the space in which all other non-binary forms of sexual and gender identity reside - a boundary free zone in which fences are crossed for the fun of it, or simply because some of us can't be fenced in. It challenges either/or categorization in favour of largely unmapped possibilities and the intense charge that comes with transgression. It acknowledges the pleasure of that transgression, as well as the need to transgress limits that do not make room for all of us" (1997: 23).

Describe queer theory, identifying some of its key concepts and goals, and comment on whether or not you believe that sexuality is as valid an area of study in popular culture as, for example, race, class, and gender.

Figure 6 
exception, as opposed to the rule. Expecting such a significant psychic shift in all students would undoubtedly set a professor up for disappointment. But if we do not begin - or continue - to teach toward goals of critical thinking and social action, those goals will not be achieved. The queer classroom - or any classroom in which identity is questioned, challenged, or destabilized - cannot be realized without taking the 'baby steps' of such activities as those described in this paper. For instructors (particularly those of us who are not tenured), those steps can be difficult and dangerous. Even if job security is not threatened, personal security and professional authority can be. As Didi Khayatt mentions, outing oneself in the classroom can cause an "irrelevant distinction" between personal identity and course material, with the professor becoming the text (39). I would also point out the frustrating and common assumption by students that queer subject material is only relevant to the course because the instructor is queer. These assumptions, which are somtimes palpable in the classroom as well as evidenced in teaching evaluations, can be discouraging. In the few days prior to beginning almost every new session, I question myself, my position in the classroom, and the reasons behind my determination to introduce - and to be - a queer presence in my classroom. But at some level, as a teacher, I am compelled to teach the things that I wish I had been taught. The decision by any instructor consciously to incorporate queerness into pedagogy is not easy, tidy, or without risk, but has the potential to transgress some of academia's boundaries in large and small ways.

\section{Works Cited}

Britzman, Deborah. "Queer Pedagogy and Its Strange Techniques." Ristock and Taylor 49-71.

Bryson, Mary and Suzanne de Castell. "Queer Ethnography: Identity, Authority, Narrativity, and a Geopolitics of Text." Ristock and Taylor 97-110.

—. "Queer Pedagogy: Praxis Makes Im/perfect." Canadian Journal of Education 18 (1993): 285-305.

Darsey, James. “Die Non.” Queer Words, Queer Images. New York:

New York University Press, 1994. 45-76.

Ellsworth, Elizabeth. "Why Doesn't This Feel Empowering? 
Working through the Repressive Myths of Critical Pedagogy." Feminisms and Critical Pedagogy. Eds. Carmen Luke and Jennifer Gore. New York: Routledge, 1992.

Hammer, Barbara. "The Politics of Abstraction." Queer Looks: Perspectives on Lesbian and Gay Film and Video. Eds. Martha Gever, John Greyson, and Pratibha Parmar. Toronto: Routledge, 1993. 70-76.

Haraway, Donna. “A Manifesto for Cyborgs: Science, Technology, and Socialist Feminism in the 1980s." Feminism/Postmodernism. New York: Routledge, 1990. 190-233.

Khayatt, Didi. "Paradoxes of the Closet: Beyond the Classroom Assignment of In or Out." Ristock and Taylor 31-48.

Queen, Carol and Laurence Schimel. Pomosexuals: Challenging Assumptions about Gender and Sexuality. San Francisco: Cleis, 1997.

Rich, Adrienne. "Compulsory Heterosexuality and Lesbian Existence." Adrienne Rich's Prose and Poetry. Ed. Barbara Charlesworth Gelpi and Albert Gelpi. New York: Norton, 1993. 203-24.

Ristock, Janice and Catherine Taylor. Inside the Academy and Out: Lesbian/Gay/Queer Studies and Social Action. Toronto: University of Toronto Press, 1998.

-. "Introduction." Ristock and Taylor 3-9.

Sedgewick, Eve Kosofsky. "Queer and Now.” Tendencies. Durham: Duke University Press, 1993.

Weed, Elizabeth. "Introduction." Feminism Meets Queer Theory. Ed. Elizabeth Weed and Naomi Schor. Bloomington: Indiana University Press, 1997. vii-xiii.

Wood, Julia. Communication Theories in Action. California:

Wadsworth, 2000. 